\title{
A Model of the Renal Cortex and Medulla*
}

\author{
JOHN A. JACQUEZ. \\ Department of Physiology. The Medical School, and Department of Biostatistics, \\ The School of Public Health. The University of Michigan, Ann Arbor, Michigan \\ BRICE CARNAHAN \\ Department of Chemical Engineering. The Engineering School, and Department of \\ Biostatistics, The School of Public Health. The University of Michigan, Ann Arbor, \\ Michigan
}

AN D

PETER ABBRECHT

Department of Physiology, The Medical School, The University of Michigan, Ann Arbor, Micrigan

Communicated by John A. Jacquez

\begin{abstract}
Mathematical models of the renal cortex and medulla are developed. The glomerular filtration rate is treated as an input parameter. The differential equations for transfer of water and solutes are developed under the assumption that the primary driving forces are the osmotic effect of the plasma proteins and the active transport of one solute across the walls of the nephric tubules. The system of simultaneous ordinary differential equations obtained for the stationary state for constant inputs in the medulla present a multiple-point boundary-value problem of some complexity.

In the course of developing the model a number of problems were unearthed. First, it became apparent that the commonly accepted countercurrent exchange model for the medullary capillaries is not supported by anatomical studies and that a distributed capillary bed model might give a truer picture. Second, it became obvious that the information available on the sodium pump is as yet insufficient to let us decide unambiguously whether the pump is reversible or irreversible.
\end{abstract}

* This work was supported in part by grant GM 892 from the National Institutes of Health. 


\section{INTKODUCTION}

Our present knowledge of renal structure and function is well reviewed in the text by Pitts [17]. In brief, the currently accepted picture of the way the kidney functions is as follows. Approximately $80 \%$ of the glomerular filtrate is reabsorbed in the proximal tubules in an essentially isosmotic manner. Since practically all of the proximal tubules are in the cortex, this may be viewed as a cortical function. Concentration of the urine occurs in the medulla. Two hypotheses dominate our present view of inedullary function. One is that the Henle loop acts as a countercurrent multiplier by actively pumping sodium ions out of the ascending limb. The other and independent hypothesis is that the medullary capillaries are also arranged in a hairpin configuration, like the loops of $\mathrm{H}$ mle, and act as countercurrent exchangers. The evidence supporting the first of these hypotheses is strong; that supporting the second is weak, and in fact recent anatomical studies suggest that the medullary capillaries are not arranged in the hairpin configuration $[14,18]$.

It would be most useful, in our thinking and speculation about renal function, to have avalable a mathematical model of the whole kidney that incorporates the major features of renal structure and the major hypotheses of renal function. Many models of particular features of renal structure and function have been proposed $[1-4,12,13,16,23,24]$. In all of these only a portion of the kidney, for example the proximal tubules or Henle's loop, is modeled. The model of the medulla of Pinter and shohet $[16]$ appears to be unrealistic to us because it neglects water movements. A complete model with both cortex and medulla is needed. Stril a model should incorporate only the major features of renal structure and should be capable of showing the typical response of the mammalian kidney in water deprivation, water diuresis, and osmotic diuresis.

In this paper we attempt to formulate such a model and we discuss in some detail the reasons for including various features in the model.

FORMULATION OF MODEL: ANATOMICAL AND PHYSIOLOGICAL CONSIDERATIONS

Although structurally there is a small transition zone between the cortex and medulia, for the most part the cortex and medulla are separate and distinctively different in structure; we neglect the transition zone and assume that the cortex and medulla are separated by a sharp bound- 
ary. Although Henle's loop as commonly described in anatomical texts includes portions of both proximal and distal tubules, it is more convenient to treat it as a distinct unit. Hence for the purposes of this paper we consider the nephric tubules to consist of three portions, proximal tubule, Henle's loop, and distal tubule. We include the proximal and distal tubules of the juxtamedullary nephrons in the model of the cortex, and assume that the strictly cortical nephrons consist primarily of proximal and distal tubules with a small Henle's section.

\section{The cortex}

The basic assumptions used to derive a model of the cortex follow.

Assumption 1. Flow in the tubules and capillaries is a bulk displacement flow with uniform mixing in a direction perpendicular to the axes of these tubes. In effect we assume a uniform fiuid velocity at any cross section in one of the tubes and an average concentration for a solute at any fixed distance along a tubule or capillary. This is a reasonable approximation because the capillaries and nephrons have very small diameter-to-length ratios. This assumption has been used by Bergmann and Dikstein [1], Burgen [2], Dole [3], Kelman [12], Kuhn and Ramel [13], Wesson [24], and Pinter and Shohet [16]. We further assume that volume changes are entirely attributable to the water movements.

Assumption 2. We assume uniform and rapid mixing of the interstitial fluid of the cortex. In effect we assume that there are no significant concentration gradients in the interstitial fluid and that we can use a mean concentration of any solute in the interstitial fluid in our equations. The fact that there is no structural orientation in the cortex favors this assumption. The close juxtaposition of different elements in the cortex also provides support for this assumption since a small portion of interstitial fluid may contact portions of proximal tubules, distal tubules, and the capillary network. Furthermore the capillary net from one glomerulus anastomoses freely with those from neighboring nephrons. Physiological evidence in support of this assumption is provided by observations mentioned by Pitts ([17], page 102). If inulin and labeled sulfate are injected into the renal artery, sulfate appears in the urine before inulin does. Inulin does not cross the wall of the nephron but sulfate does, hence this observation provides some evidence for down- 
stream transfer of sulfate through the interstitial fluid. Wesson [24] used this assumption in his treatment of urea excretion.

Assumption 3. We neglect the thin segment of Henle's loop for the cortical nephrons but allow for a short thick segment. These are reasonable assumptions because the cortical nephrons have rather small loops of Henle and many have no thin segments. The thin segments and distinctive hairpin arrangement are a unique structural feature of the medulla and come primarily from the juxtamedullary glomeruli.

Assumption 4. The proximal and distal tubules of the juxtamedullary glomeruli are included in the cortex. This seems reasonable since the medulla consists almost entirely of Henle's loops, collecting tubules, and blood vessels. We include the capillary networks of the proximal and distal tubules of the juxtamedullary nephrons with the cortical capillary beds and treat the medullary capillary networks as separate and restricted to the medulla.

Assumption 5. The functioning of the cortex should be represented as a summation of effects contributed by each of the cortical nephrons and capillaries. We replace the approximately $1.05 \cdot 10^{6}$ cortical nephrons

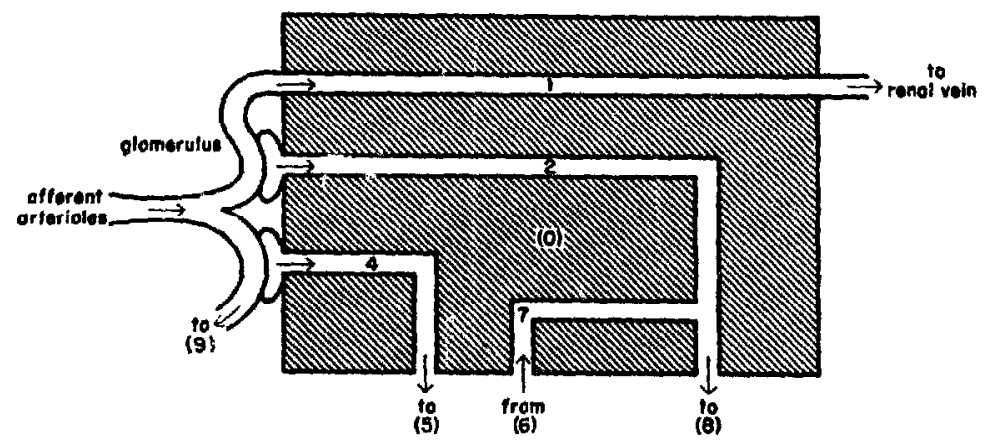

FIG. 1. Schematic of model of cortex: 0 , interstitial fluid; 1, cortical capillary bed; 2. corrical nephrons; 4, 7, proximal and distal tubules of juxtamedullary glomeruli.

[17] by one lumped tubule of length equal to the average length of these tubules and with total surface area and cross-sectional area per unit length equal to that of the sum for these tubules. The cortical capillary beds are similarly lumped. This assumption has been used in many previous treatments $[3,23,24]$. For the stationary state (vide infra), we assume 
that the cross-sectional area and surface area per unit length are constant along the capillary bed and for the proximal and distal tubules separately.

The model of the cortex that has just been outlined is summarized schematically in Fig. 1.

\section{The medulla}

Because of the unique structural arrangements in the medulla some of the assumptions made for the cortex do not hold. The collecting ducts and Henle's loops run parallel to one another in the medulla. We refer to the direction parallel to these tubes as the longitudinal axis of the medulla. The basic assumptions are again presented.

Assumption 1. Although the loops of Henle are not all of the same length, we assume that they are and use one lumped model for all of the descending limbs and another for all of the ascending limbs. We use the commonly accepted hypothesis that active transport is restricted to the ascending limb; however, the model can be modified to include active transport in the descending limb of Henle's loop if necessary.

Assumption 2. The collecting tubules are assumed to begin at the medullary boundary and to be of the same length as the limbs of the loop of Henle.

Assumption 3. As for the cortical model, we assume bulk displacement flow (plug flow) in each tubule and uniform concentration of any solute inside a tube throughout a cross section at any distance along the length of each tubule.

Assumption 4. The interstitial fluid of the medulla is assumed uniformly mixed only in a direction perpendicular to the longitudinal axis. The interstitial fluid may be viewed as contained in another impermeable tubule running in the direction of the longitudinal axis, a tubule that contains all the other tubules and capillaries and with which all the other tubules interchange solutes and water. So as not to prejudge the issue, we include the possibility of a longitudinal flow of interstitial fluid in the model.

Assumption 5. There is some doubt about the structure of the medullary capillary beds. At least two models are possible and we will examine both. 
The picture commonly presented in the textbooks [17] is that the blood vessels form hairpin loops similar in shape to Henle's loop and act as countercurrent exchangers. We refer to this as the countercurrent exchange model of the medulla. However, there is now anatomical evidence for \& quite different arrangement. Plakke and Pfeiffer [18] report that, "...the vasa recta arise in leashes from the efferent arterioles of the juxtamedullary glomeruli and descend, many as unbranched vessels, in parallel bundles to break up into capillary plexuses at different levels of the medulla." They further report that the capillary plexuses are most dense in the outer zone of the medulla, adjacent to the cortex, and that this zonation appears to be correlated with the ability to form a concentrated urine. In the model based on this picture we assume that the vasa recta are nonexchanging conduits and lump the capillary plexuses as a set of capillaries that run perpendicular to the longitudinal axis of the medulla and are distributed at different levels with mosr lying in the outer zone. Because we have assumed complete mixing in the interstitial fluid at any distance down the longitudinal axis, capillaries at one level are all bathed by interstitial fluid of constant composition. We call this model the distributed capillary bed model of the medulla. Schematic diagrams of these two models are shown in Figs. 2 and 3.

In the model we consider only three solutes. One, $u$, is actively transported across the walls of the tubules of the nephrons; the other two, $x$ and $\alpha$, are not actively transported. One of these, $x$, may be thought of as urea; the other, $w$, will be needed when we consider osmotic diuresis. Although $u$ may be thought of as sodium, we treat $u$ as a nonionic solute. Including the ionic nature of the transported solute would make this already complicated model even more difficult to handle and we suspect that the essential feature required is the active transport of an osmotically active solute. In any case, we believe that the model can be expanded to include this feature later. Thus only two driving forces that can lead to solute and solvent movement are included in the model, active transport of solute $u$ between the nephric tubules and interstitial fluid and the osmotic effect of the proteins in the capillary plasma. The interstitial fluid and glomerular filtrate are treated as free of protein. Except for the active transport of $u$, the movement of solute and solvent is assumed to follow Fick's law.

Two effects are neglected in this first model, the Donnan effect and the interaction between solute and solvent movement described by the cross coefficients in the phenomenological laws for diffusion as postulated 
in irreversible thermodynamics. Hence we do not include a reflection coefficient for each solute. The interaction terms might be important for the more permeable solutes. We have not tried to model the process of glomerular filtration; the glomerular filtration rates are treated as input parameters of the model. Possible effects of pressure gradients on solute and solvent movement across the tubular walls have not been included in this model.

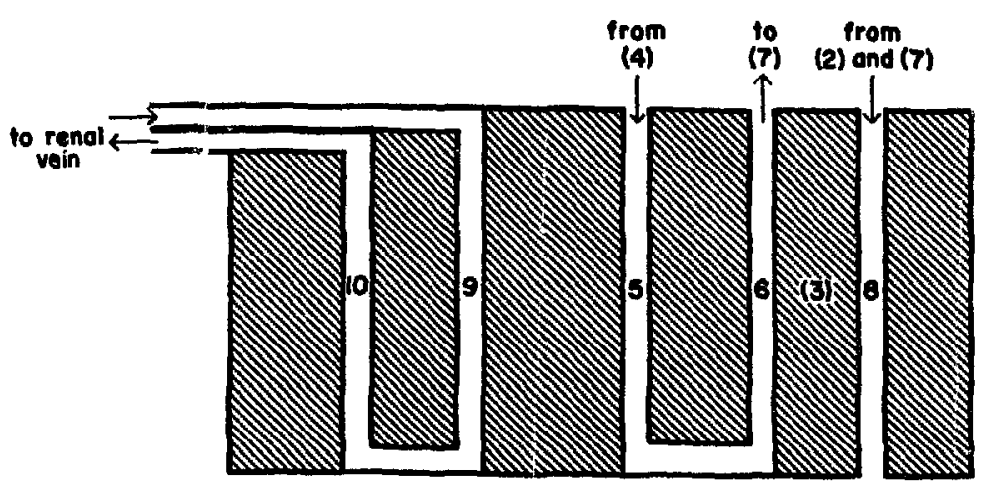

Fig. 2. Schematic of the countercurrent exchange model of the medulla: 3, interstitial space; 5, 6, descending and ascending limbs of Henle's loop; 8 , collecting tubules; 9, 10, descending and ascending limbs of capillary loops.

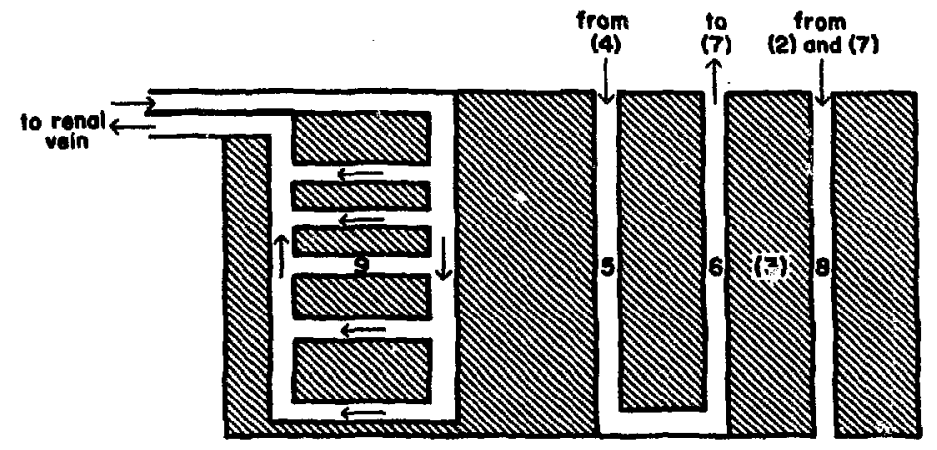

FIG. 3. Schematic of the distributed capillary bed model of the medulla: 9, capillaries distributed at different levels in the medulla.

Concentrations are given in millimoles per cubic centimeter or milliosmoles per cubic centimeter. These units are assumed to be equivalent for the solutes $u, x$, and $w$. For the proteins in plasma, the units milliosmoles per cubic centimeter are used. 
NOTATION

We use the following notation in the equations that are derived in the next section. The index $i$ associated with each tubule (see Figs. 1-3) is used as a subscript.

distance along tubules in the cortex, $\mathrm{cm}$

$\eta \quad$ distance into medulla from the corticomedullary boundary, $\mathrm{cm}$

distance along capillaries in the distributed capillary bed model of the medulla, $\mathrm{cm}$

$t \quad$ time, $\mathrm{min}$

$k_{u_{i}}, k_{x_{i}}, k_{w_{i}}$ permeability of tubule $i$ to $u, x$, and $w$, respectively, $\mathrm{cm} / \mathrm{min}$ $h_{i} \quad$ permeability of tubule $i$ to water, $\mathrm{cm}^{4} / \mathrm{milliosmole-min}$

$l_{i} \quad$ length of tubule $i, \mathrm{~cm}$

$\Lambda_{i}(t) \quad$ cross-sectional area of tubule $i$ at time $t, \mathrm{~cm}^{2}$. This is assumed to be independent of distance for any one tubule. However, this assumption does not appear in the stationary-state equations and is not essential for the argument.

$S_{i} \quad$ surface area per unit length of tubule $i, \mathrm{~cm}^{2} / \mathrm{cm}$. We assume the $S_{i}$ are piecewise constant; that is, constant for each anatomically distinct tubule such as the proximal or distal tubules.

$V_{\text {ip }} \quad$ volume of cortical interstitial fluid, $\mathrm{cm}^{3}$

$\mathrm{Ki}, \quad$ Permeability per unit length of tube $i$ to water under an osmotic gradient. This is really a product of the permeability constant $k_{v_{i}}$ and the surface area per unit length of tubule $S_{i}$. We assume it is piecewise constant. Units: $\mathrm{cm}^{5} /$ milliosmolemin. $K_{u_{i}}, K_{x_{i}}, K_{w_{i}} \quad$ permeabilities per unit length of tube $i$ for solutes $u$, $x$, and $w$. Again these are products of true permeabilities and surface areas and are assumed to be piecewise constant; thus $K_{u_{i}}=k_{u_{i}} \cdot S_{i}$. Units: $\mathrm{cm}^{2} / \mathrm{min}$.

$p_{\mathrm{I}}(\xi, t), \dot{p}_{9}(\eta, t), p_{10}(\eta, t) \quad$ concentration of protein in tubule 1 in cortex and tubules 9 and 10 in countercurrent exchange model of medulla, milliosmoles $/ \mathrm{cm}^{3}$

$p_{g}(\zeta, \eta, t)$ Concentration of protein at distance $\zeta$ along the length of the capillary tubules, which lie at a depth $\eta$, in the distributed capillary bed model of the medulla, milliosmoles $/ \mathrm{cm}^{3}$.

$u_{0}(t) \quad$ concentration of transported solute in interstitial fluid of cortex, mmoles $/ \mathrm{cm}^{3}$ 
$u_{i}(\xi, t), u_{i}(\eta, t) \quad$ concentration of actively transported solute at distance $\xi$ or $\eta$ down tubule $i$ in the cortex and countercurrent exchange model of medulla, respectively. The units of concentration, mmoles $/ \mathrm{cm}^{3}$, are assumed equivalent to the units milliosmoles $/ \mathrm{cm}^{3}$.

$u_{9}(\zeta, \eta, t)$ Concentration of the transported solute at distance $\zeta$ down the capillary tubules, which lie at depth $\eta$, in the distributed capillary bed model of the medulla, mmoles $/ \mathrm{cm}^{3}$.

$v_{i}(\xi, t) \quad$ volume flow rate in $\mathrm{cm}^{3} / \mathrm{min}$ in cortical tube $i$ at time $t$ at distance $\xi$ along the tubule. For the capillaries this refers to plasma flow, not blood flow.

$v_{i}(\eta, t) \quad$ volume flow rate in tube $i$ in the medulla at time $t$ and distance $\eta$ from the corticomedullary boundary, including the interstitial fluid as tube $i=3$. For the countercurrent exchange model of the medulla, $i=\mathbf{9}$ and $\mathbf{1 0}$ for the descending and ascending limbs, respectively, of the vasa recta. Units: $\mathrm{cm}^{3} / \mathrm{min}$.

$v_{9}(\zeta, \eta, t) \quad$ Volume flow rate at time $t$ and distance $\zeta$ along the length of the capillary tubules, which lie it a depth $\eta$, in the distributed capillary bed model of the medulla, $\mathrm{cm}^{3} / \mathrm{min}$.

$x_{0}(t), v_{0}(t)$ concentrations of the nontransported solutes in interstitial fluid of cortex, mmoles $/ \mathrm{cm}^{3}$

$x_{i}(\xi, t), w_{i}(\xi, t), x_{i}(\eta, t), w_{i}(\eta, t) \quad$ Concentrations of the two solutes that are not actively transported in tubule $i$, in cortex, and in countercurrent exchange model of medulla, respectively; mmoles $/ \mathrm{cm}^{3}$.

$x_{9}(\zeta, \eta, t), w_{9}(\zeta, \eta, t) \quad$ Concentrations of the nontransported solutes at distance $\zeta$ down the capillary tubules, which lie at a depth $\eta$, in the distributed capillary bed model of the medulla, $\mathrm{mmoles} / \mathrm{cm}^{3}$.

$T_{i}\left(u_{i}(\xi), u_{0}\right), T_{:}\left(u_{i}(\eta), u_{3}(\eta)\right) \quad$ The function that describes the transport of $u$ from the inside to the outside of tube $i$ in the cortex or in the medulla. For tube 2, for example, this would be $T_{2}\left(u_{2}(\xi), u_{0}\right)$. The transport term is written $S_{2} T_{2}\left(u_{2}, u_{0}\right)$ where $S_{2}$, the surface area per unit length, is piecewise constant and $T_{2}$ might be a different function for each of the different portions of the tubule. Thus $S_{2}$ and $T_{2}$ might differ for the proximal and distal tubules in the cortex. Units of $T: \mathrm{mmoles} / \mathrm{cm}^{2}-\mathrm{min}$. 
FORMULATION OF MATHEMATICAL MODEL

We derive the basic equations first for the cortex and then for the medulla.

The cortex

Tle capillary bed

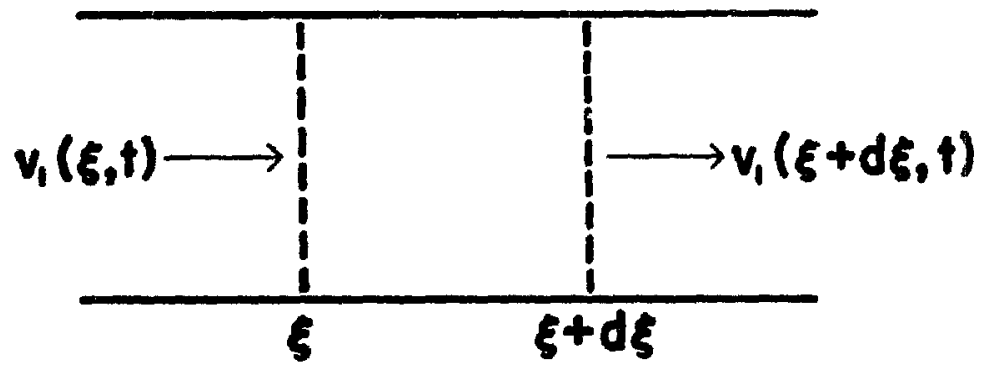

FIG. 4. Schematic diagram of flow in capillary bed.

Volume. In Fig. 4, consider the infinitesimal segment of capillary tubule (tube 1$),(\xi, \xi+d \xi)$ at a distance $\xi$ down the length of the capillaries. The volume of this element is $A_{1}(t) d \xi$. The rate of change of volume in this segment is the volume flow rate entering at minus the volume flow rate leaving at $\xi+d \xi$ plus the rate of entry of water under the osmotic gradient across the wall.

$$
\begin{aligned}
\frac{\partial}{\partial t}\left[A_{1}(t)\right] d \xi= & v_{1}(\xi, t)-v_{1}(\xi+d \xi, t) \\
& +K_{v_{2}}\left[p_{1}(\xi, t)+u_{1}(\xi, t)+x_{1}(\xi, t)+w_{1}(\xi, t)\right. \\
& \left.-u_{0}(t)-x_{0}(t)-w_{0}(t)\right] d \xi .
\end{aligned}
$$

The protein concentration is in milliosmoles per cubic centimeter. Expanding $v_{1}(\xi+d \xi, t)$ in a Taylor's series, retaining only the first-order terms in $d \xi$ and simplifying, gives $\mathrm{Eq}_{\mathrm{q}} .2$.

In order to simplify notation, we do not carry the independent variables in the remaining equations since they are obvious from the context and the section on notation.

$$
\frac{\partial A_{1}}{\partial t}=-\frac{\partial v_{1}}{\partial \xi}+K_{v_{1}}\left(p_{1}+u_{1}+x_{1}+w_{1}-u_{0}-x_{0}-w_{0}\right)
$$


Solutes. Again consider the unit of volume shown in Fig. 4. The total amount (millimoles) of solute $u$ in this volume is $A_{1} u_{1} d \xi$. Its rate of change with time is the rate at which $u$ enters at $\xi, v_{1}(\xi, t) u_{1}(\xi, t)$, minus the rate at which it leaves at $\xi+d \xi, v_{1}(\xi+d \xi, t) u_{1}(\xi+d \xi, t)$, plus the rate at which it enters across the wall, $K_{u_{1}}\left(u_{0}-u_{1}\right) d \xi$, giving Eq. 3.

$$
\frac{\partial\left(A_{1} u_{1}\right)}{\partial t}=-\frac{\partial\left(u_{1} v_{1}\right)}{\partial \xi}+K_{u_{1}}\left(u_{0}-u_{1}\right) .
$$

Similar equations must hold for $x$ and $๗$.

\section{The cortical nephrons}

The equations for the cortical nephrons are similar to those for the capillaries except for the absence of protein and the inclusion of a transport function to describe the pumping of $u$ from the tubular fluid into the interstitial fluid. The nature of this function and its relation to models of carrier transport will be discussed later. The transport function $S_{2} T_{2}\left(u_{2}, u_{0}\right)$ represents the rate at which $u$ is transported per unit length of tubule from inside the tubuie into the interstitial fluid. Hence it enters the equations with a minus sign. The equations for the cortical nephrons then become the following.

Volume

$$
\frac{\partial A_{2}}{\partial t}=-\frac{\partial v_{2}}{\partial \xi}+K_{v_{3}}\left(u_{2}+x_{2}+w_{2}-u_{0}-x_{0}-w_{0}\right)
$$

Solutes

$$
\begin{aligned}
& \frac{\partial\left(A_{2} u_{2}\right)}{\partial t}=-\frac{\partial\left(u_{2} v_{2}\right)}{\partial \xi}+K_{u_{2}}\left(u_{0}-u_{2}\right)-S_{2} T_{2}\left(u_{2}, u_{0}\right) . \\
& \frac{\partial\left(A_{2} x_{2}\right)}{\partial t}=-\frac{\partial\left(x_{2} v_{2}\right)}{\partial \xi}+K_{x_{3}}\left(x_{0}-x_{\Sigma_{2}}\right) . \\
& \frac{\partial\left(A_{2} w_{2}\right)}{\partial t}=-\frac{\partial\left(w_{2} v_{2}\right)}{\partial \xi}+K_{w_{2}}\left(w_{0}-w_{2}\right) .
\end{aligned}
$$

Note that we use the same independent variable, $\xi$, for the distance along the nephron as for distance along the capillaries; this causes no difficalty because the two sets of differential equations interact only 
indirectly through the space-independent concentrations in the interstitial fluid. A similar set of equations holds for the proximal and distal tubules of the juxtamedullary nephrons (tubes 4 and 7 , respectively); only the subscripts change.

\section{Cortical interstitial fluid}

The conservation equations for volume and total solutes in the cortical interstitial fluid are obtained by integrating the flows across the walls of all of the cortical tubules and across the corticomedullary boundary.

\section{Volume}

$$
\begin{aligned}
\frac{d V_{0}}{d t}= & -\int_{0}^{L_{1}} K_{v_{1}}\left(p_{1}+u_{1}+x_{1}+w_{1}-u_{0}-x_{0}-w_{0}\right) d \xi \\
& -\int_{0}^{L_{2}} K_{v_{2}}\left(u_{\xi_{4}}+x_{2}+w_{2}-u_{0}-x_{0}-w_{0}\right) d \xi \\
& -\int_{0}^{L_{i}} K_{v_{4}}\left(u_{4}+x_{4}+w_{4}-u_{0}-x_{0}-w_{0}\right) d \xi \\
& -\int_{0}^{L_{7}} K_{v_{7}}\left(u_{7}+x_{7}+w_{7}-u_{0}-x_{0}-w_{0}\right) d \xi \\
& -v_{3}(0, t) .
\end{aligned}
$$

The volume flow rate of interstitial fluid between cortex and medulla, $v_{3}(0, t)$, is defined as positive when into the medulla. We neglect movement of water or solutes by diffusion across the corticomedullary boundary.

Solutes. For the transported solute $x$ the equation becones

$$
\begin{aligned}
\frac{d\left(u_{0} V_{0}\right)}{d t}= & -\int_{0}^{I_{1}} K_{u_{1}}\left(u_{0}-u_{1}\right) d \xi-\int_{0}^{L_{2}}\left[K_{u_{2}}\left(u_{0}-u_{2}\right)-S_{2} T_{2}\left(u_{2}, u_{0}\right)\right] d \xi \\
& -\int_{0}^{L_{4}}\left[K_{u_{4}}\left(u_{0}-u_{4}\right)-S_{4} T_{4}\left(u_{4}, u_{0}\right)\right] d \xi
\end{aligned}
$$




$$
-\int_{0}^{L_{t}}\left[K_{u_{1}}\left(u_{0}-u_{7}\right)-S_{7} T_{7}\left(u_{7}, u_{0}\right)\right] d \xi-u_{0} v_{3}(0, t)
$$

The equations for the other solutes, $x$ and $w$, are similar except for the absence of the transport terms.

$$
\begin{aligned}
\frac{d\left(x_{0} V_{0}\right)}{d t}= & -\int_{0}^{L_{1}} K_{x_{1}}\left(x_{0}-x_{1}\right) d \xi-\int_{0}^{L_{2}} K_{x_{2}}\left(x_{0}-x_{2}\right) d \xi \\
& -\int_{0}^{L_{4}} K_{x_{4}}\left(x_{0}-x_{4}\right) d \xi-\int_{0}^{L_{1}} K_{x_{4}}\left(x_{0}-x_{7}\right) d \xi-x_{0} v_{3}(0, t) . \\
\frac{d\left(w_{0} V_{0}\right)}{d t}= & -\int_{0}^{L_{1}} K_{w_{1}}\left(w_{0}-w_{1}\right) d \xi-\int_{0}^{L_{2}} K_{w_{3}}\left(w_{0}-w_{2}\right) d \xi \\
& -\int_{0}^{L_{1}} K_{w_{4}}\left(w_{0}-w_{4}\right) d \xi-\int_{0}^{L_{7}} K_{w_{7}}\left(w_{0}-w_{7}\right) d \xi-w_{0} v_{3}(0, t) .
\end{aligned}
$$

\section{Medulla}

The equations for the medulla differ for the countercurrent exchange model and the distributed capillary bed model; however, the equations for Henle's loops and collecting ducts are the same for both models so we present these first.

\section{Loop of Henle}

The equations for the ascending and descending limbs of the loop of Henle are almost the same, differing only in (1) the values of the physical parameters, (2) the boundary conditions, and (3) the presence or absence of $\approx$ term for the transport of $u$.

Volume. By a derivation that is essentially the same as that used for the cortex, the equation for volume change in the descending tubule becomes

$$
\frac{\partial A_{5}}{\partial t}=-\frac{\partial v_{5}}{\partial \eta}+K_{v_{s}}\left(u_{5}+x_{5}+w_{5}-u_{3}-x_{3}-w_{3}\right)
$$


Here $u_{3}, x_{3}$ and $w_{3}$ are functions of $\eta$. The same equation holds for the ascending limb (tube 6) except for a change in subscript.

Solutes. For the transported solute $u$ we of . in $\mathrm{E}_{1} .13$ for the descerding limb.

$$
\frac{\partial\left(u_{5} A_{5}\right)}{\partial t}=-\frac{\partial\left(u_{5} v_{5}\right)}{\partial \eta}+K_{u_{s}}\left(u_{3}-u_{5}\right) .
$$

A term for the transport of $u,-S_{5} T_{5}\left(u_{5}, u_{3}\right)$, can be adde $t$ if needed in further studies. The corresponding equation for the ascending limb contains a term for the transport of $u$.

$$
\frac{\partial\left(u_{6} A_{6}\right)}{\partial t}=-\frac{\partial\left(u_{6} v_{6}\right)}{\partial \eta}+K_{u_{6}}\left(u_{3}-u_{6}\right)-S_{6} T_{6}\left(u_{6}, u_{3}\right) .
$$

The equation for $x_{5}$ is

$$
\frac{\partial\left(x_{5} A_{5}\right)}{\partial t}=-\frac{\partial\left(x_{5} v_{5}\right)}{\partial \eta}+K_{x_{5}}\left(x_{3}-x_{5}\right) .
$$

Similar equations hold for $w_{5}, x_{6}$, and $u_{6}$.

\section{Collecting ducts}

For the collecting ducts a similar set of equations holks Eqs. (16-19).

$$
\begin{aligned}
\frac{\partial A_{8}}{\partial t} & =-\frac{\partial v_{8}}{\partial \eta}+K_{v_{8}}\left(u_{8}+x_{8}+w_{8}-u_{3}-x_{3}-w_{3}\right) . \\
\frac{\partial\left(A_{8} u_{8}\right)}{\partial t} & =-\frac{\partial\left(u_{8} v_{8}\right)}{\partial \eta}+K_{u_{8}}\left(u_{3}-u_{8}\right)-S_{8} T_{8}\left(u_{8}, u_{3}\right) . \\
\frac{\partial\left(A_{8} x_{8}\right)}{\partial t} & =-\frac{\partial\left(x_{8} v_{8}\right)}{\partial \eta}+K_{x_{8}}\left(x_{3}-x_{8}\right) . \\
\frac{\partial\left(A_{8} w_{8}\right)}{\partial t} & =-\frac{\partial\left(w_{8} v_{8}\right)}{\partial \eta}+K_{w_{8}}\left(w_{3}-w_{8}\right) .
\end{aligned}
$$

The countercurrent exchange model

For the countercurrent exchange model (Fig. 2), the medullary capillaries are treated as longitudinally oriented with descending and ascending limbs like those of the loops of Henle. 
Capillaries. The equations for the capillaries are like those for the limbs of Henle's loop except for the absence of the active transport term and the presence of the protein.

$$
\frac{\partial A_{9}}{\partial t}=-\frac{\partial v_{9}}{\partial \eta}+K_{v_{9}}\left(p_{9}+u_{9}+x_{9}+w_{9}-u_{5}-x_{3}-w_{3}\right) .
$$

A similar equation holds for the ascending limb, tube 10. For the solutes the equations are of the form

$$
\frac{\partial\left(A_{9} u_{9}\right)}{\partial t}=-\frac{\partial\left(v_{9} u_{\theta}\right)}{\partial \eta}+K_{u_{0}}\left(u_{3}-u_{9}\right)
$$

with similar equations for $x_{9}, w_{9}, u_{10}, x_{10}$, and $w_{10}$.

Interstitial fluid. For the interstitial fluid the same approach leads to the following rather messy equations.

$$
\begin{aligned}
\frac{\partial A_{3}}{\partial t}= & -\frac{\partial v_{3}}{\partial \eta}+K_{v_{6}}\left(u_{3}+x_{3}+w_{3}-u_{5}-x_{5}-w_{5}\right) \\
& +K_{v_{8}}\left(u_{3}+x_{3}+w_{3}-u_{6}-x_{5}-w_{6}\right) \\
& +K_{v_{8}}\left(u_{3}+x_{3}+w_{3}-u_{8}-x_{8}-w_{8}\right) \\
& +K_{v_{8}}\left(u_{3}+x_{3}+w_{3}-p_{9}-u_{9}-x_{9}-w_{9}\right) \\
& +K_{v_{10}}\left(u_{3}+x_{3}+w_{3}-p_{10}-u_{10}-x_{10}-w_{10}\right) \\
\frac{\partial\left(A_{3} u_{3}\right)}{\partial t}= & -\frac{\partial\left(u_{3} v_{3}\right)}{\partial \eta}+K_{u_{5}}\left(u_{5}-u_{3}\right)+K_{u_{6}}\left(u_{6}-u_{3}\right)+K_{u_{8}}\left(u_{8}-u_{3}\right) \\
& +K_{u_{9}}\left(u_{9}-u_{3}\right)+K_{u_{i_{0}}}\left(u_{10}-u_{3}\right)+S_{6} T_{6}\left(u_{6}, u_{3}\right)+S_{8} T_{8}\left(u_{8}, u_{3}\right) \\
\frac{\partial\left(A_{3} x_{3}\right)}{\partial t}= & -\frac{\partial\left(x_{3} v_{3}\right)}{\partial \eta}+K_{x_{3}}\left(x_{5}-x_{3}\right)+K_{x_{6}}\left(x_{6}-x_{3}\right) \\
& +K_{x_{8}}\left(x_{8}-x_{3}\right)+K_{x_{9}}\left(x_{9}-x_{3}\right)+K_{x_{10}}\left(x_{10}-x_{3}\right)
\end{aligned}
$$

A similar equation holds for $w_{3}(\eta, t)$.

The distributed capillary bed model

For this model let $v_{9}(0, t)$ be the total blood flow to the medullary capillary bed and let $A_{9}$ represent the total cross-sectional area of the medullary capillary bed. Let $f(\eta) d \eta$ be the fraction of the capillaries lo- 
cated between $\eta$ and $\eta+d \eta$ in the medulla, where $\int_{0}^{L_{0}} f(\eta) d \eta=1$. It is assumed these capillaries run in a direction perpendicular to the $\eta$ axis. Then $v_{g}(0, t) f(\eta) d \eta$ and $A_{g} /(\eta) d \eta$ are the fractions of the initial volume flow and of the total cross-sectional area over an incremental depth $d \eta$ at depth $\eta$ in the medulla. The transfer constants now also depend on $\eta$ through the density function $f(\eta)$; for example, the transfer constant for $u$ for those capillaries lying between $\eta$ and $\eta+d \eta$ must be $K_{u_{s}} f(\eta) d \eta$, where $K_{u,}$ is the constant for the entire capillary bed. Let $\zeta$ represent distance along the capillary bed. We assume, for simplicity, that all of the capillaries are of length $L_{9}$. The quantities $v_{9}, u_{9}, x_{9}$, $v_{9}$ are now to be considered functions of both $\eta$ and $\zeta$. The volume flow rate at time $t$ at distance $\zeta$ along the capillary bed and between $\eta$ and $\eta+d \eta$ is $v_{9}(\zeta, \eta, t) d \eta$; thus $v_{8}(\zeta, \eta, t)$ is a volume flow density.

Capillaries

$$
\begin{aligned}
\frac{\partial\left[A_{9} f(\eta)\right]}{\partial t} & =-\frac{\partial v_{9}}{\partial \zeta}+K_{v_{g}} f(\eta)\left(p_{9}+u_{9}+w_{9}-u_{3}-x_{3}-w_{3}\right) . \\
\frac{\partial\left[A_{9} f(\eta) u_{9}\right]}{\partial t} & =-\frac{\partial\left(v_{g} u_{g} j\right.}{\partial \zeta}+K_{u_{g}} f(\eta)\left(u_{3}-u_{9}\right) .
\end{aligned}
$$

Equations similar to Eq. 26 apply for the other solutes, $x_{8}$ and $w_{9}$.

\section{The interstitial space}

The equations for the interstitial space are quite involved since they must include, for any $\eta$, and integral over thie length of the capillary, $L_{\theta}$. They are:

$$
\begin{aligned}
\frac{\partial\left(A_{3}\right)}{\partial t}= & -\frac{\partial v_{3}}{\partial \eta}+K_{v_{5}}\left(u_{3}+x_{3}+w_{3}-u_{5}-x_{5}-w_{5}\right) \\
& +K_{v_{6}}\left(u_{3}+x_{3}+\eta_{3}-u_{6}-x_{6}-w_{6}\right) \\
& +K_{v_{8}}\left(u_{3}+x_{3}+w_{3}-u_{8}-x_{8}-w_{8}\right) \\
& +f(\eta) \int_{0}^{L_{9}} K_{v_{9}}\left[u_{3}+x_{3}+w_{3}-p_{9}(\zeta)-x_{9}(\zeta)-u_{9}(\zeta)-w_{9}(\zeta)\right] d \zeta .
\end{aligned}
$$

For the transported solute, Eq. 28 holds. 


$$
\begin{aligned}
\frac{\partial\left(A_{3} u_{3}\right)}{\partial t}= & -\frac{\partial\left(u_{3} v_{3}\right)}{\partial \eta}+K_{u_{5}}\left(u_{5}-u_{3}\right)+K_{u_{6}}\left(u_{6}-u_{3}\right) \\
& +K_{u_{8}}\left(u_{8}-u_{3}\right)+S_{6} T_{6}\left(u_{6}, u_{3}\right) \\
& +S_{8} T_{8}\left(u_{8}, u_{3}\right)+f(\eta) \int_{0}^{L_{6}} K_{u_{8}}\left[u_{9}(\zeta)-u_{3}\right] d \zeta
\end{aligned}
$$

The corresponding equations for the nontransported solutes $x$ and $w$ are somewhat simpler; for example,

$$
\begin{aligned}
\frac{\partial\left(A_{3} x_{3}\right)}{\partial t}= & -\frac{\partial\left(x_{3} v_{3}\right)}{\partial \eta}+K_{x_{6}}\left(x_{5}-x_{3}\right)+K_{x_{6}}\left(x_{6}-x_{3}\right) \\
& +K_{x_{8}}\left(x_{8}-x_{3}\right)+f(\eta) \int_{0}^{L_{0}} K_{x_{8}}\left[x_{9}(\zeta)-x_{3}\right] d \zeta
\end{aligned}
$$

Initial and boundary conditions must be added to complete the model.

THE EQUATIONS OF THE STATIONARY STATE

The equations for the time-dependent case are extremely difficult to handle; the equations for the stationary states, however, are much more amenable to analysis and numerical investigation. We seek the timeindependent solutions under the assumptions that the initial flow rates and concentrations of solutes are constants and that the cross-sectional areas and surface areas per unit length are constants or at least piecewise constant. The set of partial differential equations then reduces to a set of ordinary differential equations. We display these for future reference; they are easily derived from the previous equations.

\section{Cortex}

Capillary bed

$$
\begin{aligned}
\frac{d v_{1}}{d \xi} & =K_{v_{1}}\left(p_{1}+u_{1}+x_{1}+w_{1}-u_{0}-x_{0}-w_{0}\right) \\
\frac{d\left(u_{1} v_{1}\right)}{d \xi} & =K_{u_{1}}\left(u_{0}-u_{1}\right) .
\end{aligned}
$$


244 JOHN A. JACQUEZ, BRICE CARNAHAN, AND PETER ABBRECHT

$$
\begin{aligned}
& \frac{d\left(x_{1} v_{1}\right)}{d \xi}=K_{x_{1}}\left(x_{0}-x_{1}\right) . \\
& \frac{d\left(w_{1} v_{1}\right)}{d \xi}=K_{w_{1}}\left(w_{0}-w_{1}\right) .
\end{aligned}
$$

For steady-state conditions with plasma of constant composition entering the kidney, let $p_{1}(0)$ and $v_{1}(0)$ be the initial protein concentration and the initial volume flow rate in the cortical capillary bed. Then by conservation of mass, $p_{1}(0) v_{1}(0)=p_{1}(\xi) v_{1}(\xi)$ and $p_{1}(\xi)=p_{1}(0) v_{1}(0) / v_{1}(\xi)$.

Cortical nephrons

$$
\begin{aligned}
\frac{d v_{2}}{d \xi} & =K_{v_{3}}\left(u_{2}+x_{2}+w_{2}-u_{0}-x_{0}-w_{0}\right) . \\
\frac{d\left(u_{2} v_{2}\right)}{d \xi} & =K_{u_{2}}\left(u_{0}-u_{2}\right)-S_{2} T_{2}\left(u_{2}, u_{0}\right) . \\
\frac{d\left(x_{2} v_{2}\right)}{d \xi} & =K_{x_{3}}\left(x_{0}-x_{2}\right) .
\end{aligned}
$$

Similar equations hold for $w_{2}$ and for the prcximal and distal tubules of the juxtamedullary nephrons (tubules 4 and 7 ). The latter can have only a small effect on the over-all operation of the cortex because there is only one juxtamedullary glomerulus for approximately every 7 cortical glomeruli $[13]$.

Cortical interstitial fluid

$$
\begin{aligned}
v_{3}(0)= & -\int_{0}^{L_{1}} K_{v_{1}}\left(p_{1}+u_{1}+x_{1}+w_{1}-u_{0}-x_{0}-w_{0}\right) d \xi \\
& -\int_{0}^{L_{2}} K_{v_{2}}\left(u_{2}+x_{2}+w_{2}-u_{0}-x_{0}-w_{0}\right) d \xi \\
& -\int_{0}^{L_{4}} K_{v_{4}}\left(u_{4}+x_{4}+w_{4}-u_{0}-x_{0}-w_{0}\right) d \xi \\
& -\int_{0}^{L_{7}} K_{v_{7}}\left(u_{7}+x_{7}+w_{7}-u_{0}-x_{0}-w_{0}\right) d \xi .
\end{aligned}
$$




$$
\begin{aligned}
u_{0} v_{3}(0)= & -\int_{0}^{L_{1}} K_{u_{1}}\left(u_{0}-u_{1}\right) d \xi-\int_{0}^{L_{2}}\left[K_{u_{2}}\left(u_{0}-u_{2}\right)-S_{2} T_{2}\left(u_{2}, u_{0}\right)\right] d \xi \\
& -\int_{0}^{L_{4}}\left[K_{u_{4}}\left(u_{0}-u_{4}\right)-S_{4} T_{4}\left(u_{4}, u_{0}\right)\right] d \xi \\
& -\int_{0}^{L_{7}}\left[K_{u_{7}}\left(u_{0}-u_{7}\right)-S_{7} T_{7}\left(u_{7}, u_{0}\right)\right] d \xi \\
x_{0} v_{3}(0)= & -\int_{0}^{L_{1}} K_{x_{1}}\left(x_{0}-x_{1}\right) d \xi-\int_{0}^{L_{4}} K_{x_{2}}\left(x_{0}-x_{2}\right) d \xi \\
& -\int_{0}^{L_{4}} K_{x_{4}}\left(x_{0}-x_{4}\right) d \xi-\int_{0}^{L_{7}} K_{x_{7}}\left(x_{0}-x_{7}\right) d \xi
\end{aligned}
$$

For $w_{0}$, add an equation similar to Eq. 39.

\section{Medulla}

Loof of Henle

$$
\begin{aligned}
\frac{d v_{5}}{d \eta} & =K_{v_{6}}\left(u_{5}+x_{5}+w_{5}-u_{3}-x_{3}-w_{3}\right) . \\
\frac{d\left(u_{5} v_{5}\right)}{d \eta} & =K_{v_{5}}\left(u_{3}-u_{5}\right) . \\
\frac{d\left(x_{5} v_{5}\right)}{d \eta} & =K_{x_{5}}\left(x_{3}-x_{5}\right) . \\
\frac{d\left(w_{5} v_{5}\right)}{d \eta} & =K_{w_{6}}\left(w_{3}-w_{5}\right) .
\end{aligned}
$$

The equations for the ascending limb (tu'se 5 , and collecting duct (tube 8) are of the same form as Eqs. 40-43 except for the addition of a transport term of form -- $S_{6} T_{6}\left(u_{6}, u_{3}\right)$ or $-S_{8} T_{8}\left(u_{8}, u_{3}\right)$ to Eq. 41. 
Countercurrent exchange model

Capillaries

$$
\begin{aligned}
\frac{d v_{9}}{d \eta} & =K_{v_{9}}\left(p_{9}+u_{9}+x_{9}+w_{9}-u_{3}-x_{3}-w_{9}\right) . \\
\frac{d\left(u_{9} v_{9}\right)}{d \eta} & =K_{u_{9}}\left(u_{3}-u_{9}\right) .
\end{aligned}
$$

Equations similar to Eq. 41 hold for $x_{9}$ and $w_{9}$. For the ascending capillaries (tube 10), the equations are identical, except for a change of the numerical subscript 9 to 10 . If $p_{9}(0)$ and $v_{9}(0)$ are the steady-state protein concentration and volume flow rate entering the medullary capillaries, then from conservation of mass, $p_{9}(\eta)=p_{9}(0) \cdot v_{9}(0) / v_{9}(\eta)$ and $p_{10}(\eta)=$ $=-p_{9}(0) v_{9}(0) / v_{10}(\eta)$.

\section{Interstitial fluid}

$$
\begin{aligned}
\frac{d v_{3}}{d \eta}= & K_{v_{8}}\left(u_{3}+x_{3}+w_{3}-u_{5}-x_{5}-w_{5}\right) \\
& +K_{v_{6}}\left(u_{3}+x_{3}+w_{3}-u_{6}-x_{6}-w_{6}\right) \\
& +K_{v_{8}}\left(u_{3}+x_{3}+w_{3}-u_{3}-x_{8}-w_{8}\right) \\
& +K_{v_{8}}\left(u_{3}+x_{3}+w_{3}-p_{9}-u_{9}-x_{9}-w_{9}\right) \\
& +K_{v_{10}}\left(u_{3}+x_{3}+w_{3}-p_{10}-u_{10}-x_{10}-w_{10}\right) . \\
\frac{d\left(u_{3} v_{3}\right)}{d \eta}= & K_{u_{6}}\left(u_{5}-u_{3}\right)+K_{u_{6}}\left(u_{6}-u_{3}\right)+K_{u_{s}}\left(u_{8}-u_{3}\right) \\
& +K_{u_{0}}\left(u_{9}-u_{3}\right)+K_{u_{50}}\left(u_{10}-u_{3}\right)+S_{6} T_{6}\left(u_{6}, u_{3}\right) \\
& +S_{8} T_{8}\left(u_{8}, u_{3}\right) . \\
\frac{d\left(x_{3} v_{3}\right)}{d \eta}= & K_{x_{5}}\left(x_{5}-x_{3}\right)+K_{x_{6}}\left(x_{8}-x_{3}\right)+K_{x_{8}}\left(x_{8}-x_{3}\right) \\
& +K_{x_{0}}\left(x_{9}-x_{3}\right)+K_{x_{10}}\left(x_{10}-x_{3}\right) .
\end{aligned}
$$

The equation for $w_{3}$ is the same form as that for $x_{3}$.

The distributed capillary bed model

Capillaries

$$
\frac{d v_{9}(\eta, \zeta)}{d \xi}=K_{v_{9}} f(\eta)\left(p_{9}+u_{9}+x_{9}+w_{9}-u_{3}-x_{3}-w_{3}\right) .
$$




$$
\frac{d\left(v_{9} u_{9}\right)}{d \zeta}=K_{u_{9}} f(\eta)\left(u_{3}-u_{9}\right)
$$

The equations for $x_{9}$ and $w_{9}$ are similar to Eq. 50 .

The interstitial space

$$
\begin{aligned}
\frac{d v_{3}}{d \eta}= & K_{v_{5}}\left(u_{3}+x_{3}+w_{3}-u_{5}-x_{5}-w_{5}\right) \\
& +K_{v_{6}}\left(u_{3}+x_{3}+w_{3}-u_{6}-x_{6}-w_{6}\right) \\
& +K_{v_{8}}\left(u_{3}+x_{3}+w_{3}-u_{8}-x_{8}-w_{8}\right) \\
& +f(\eta) \int_{0}^{L_{9}} K_{v_{9}}\left[u_{3}+x_{3}+w_{3}-p_{9}(\zeta)-u_{9}(\zeta)-x_{9}(\zeta)-w_{9}(\zeta)\right] d \zeta .
\end{aligned}
$$

$$
\begin{aligned}
\frac{d\left(u_{3} v_{3}\right)}{d \eta}= & K_{u_{5}}\left(u_{5}-u_{3}\right)+K_{u_{8}}\left(u_{6}-u_{3}\right)+K_{u_{8}}\left(u_{8}-u_{3}\right) \\
& +S_{6} T_{6}\left(u_{6}, u_{3}\right)+S_{8} T_{8}\left(u_{8}, u_{3}\right) \\
& +f(\eta) \int_{0}^{L_{9}} K_{u_{8}}\left[u_{9}(\zeta)-u_{3}\right] d \zeta
\end{aligned}
$$

$$
\begin{aligned}
\frac{d\left(x_{3} v_{3}\right)}{d \eta}= & K_{x_{5}}\left(x_{5}-x_{3}\right)+K_{x_{6}}\left(x_{6}-x_{3}\right)+K_{x_{8}}\left(x_{8}-x_{3}\right) \\
& +f(\eta) \int_{0}^{L_{9}} K_{x_{8}}\left[x_{9}(\zeta)-x_{3}\right] d \zeta
\end{aligned}
$$

\section{Initial conditions}

The conditions assumed given are the initial flow rates $v_{1}(0), v_{2}(0)$, $v_{4}(0), v_{9}(0)$ and concentrations:

$$
\begin{aligned}
& p_{1}(0)=p_{9}(0), \quad \text { milliosmoles } / \mathrm{cm}^{3} ; \\
& u_{1}(0)=u_{9}(0)=u_{2}(0)=u_{4}(0), \quad \text { mmole } / \mathrm{cm}^{3}
\end{aligned}
$$




$$
\begin{aligned}
x_{1}(0)=x_{9}(0)=x_{2}(0)=x_{4}(0), & \text { mmole } / \mathrm{cm}^{3} ; \\
w_{1}(0)=w_{9}(0)=w_{2}(0)=w_{4}(0), & \text { mmole } / \mathrm{cm}^{3} .
\end{aligned}
$$

Under the steady-state assumption these are no longer functions of time. Here we have neglected the Donnan effect in the formation of the glomerular filtrate.

\section{Boundary conditions}

The boundary conditions at the corticomedullary boundary and at the junctions of the ascending and descending limbs of Henle's loop and the ascending and descending limbs of the capillaries in the countercurrent eychange model follow from assumptions of physical continuity of flows and concentrations. For the model of the distributed capillary bed these are as follows.

$$
\begin{aligned}
v_{4}\left(L_{4}\right) & =v_{5}(0) \\
v_{5}\left(L_{3}\right) & =-v_{6}\left(L_{3}\right) \\
v_{7}(0) & =-v_{6}(0) \\
v_{8}(0) & =v_{7}\left(L_{7}\right)+v_{2}\left(L_{2}\right) \\
u_{4}\left(L_{4}\right) & =u_{5}(0) \\
u_{5}\left(L_{3}\right) & =u_{6}\left(L_{3}\right) \\
u_{7}(0) & =u_{6}(0) \\
u_{8}(0) v_{8}(0) & =u_{7}\left(L_{7}\right) v_{7}\left(L_{7}\right)+u_{2}\left(L_{2}\right) v_{2}\left(L_{2}\right)
\end{aligned}
$$

The boundary conditions on $x$ and $w$ are similar to those for $u$. For the countercurrent exchange model the following conditions must be added.

$$
\begin{aligned}
& v_{9}\left(L_{3}\right)=-v_{10}\left(L_{3}\right), \\
& u_{9}\left(L_{3}\right)=u_{10}\left(L_{3}\right), \\
& x_{9}\left(L_{3}\right)=x_{10}\left(L_{3}\right), \\
& w_{9}\left(L_{3}\right)=w_{10}\left(L_{3}\right) .
\end{aligned}
$$

THE TRANSEORT FUNCTION

Although a great deal of information has been gathered on the over-all nature of sodium resorption in the kidney, little specific information is 
available upon which to base a model of the sodium pump. The minimum data needed for at least an empirical functional description of the action of the pump are (1) measurements of total net fluxes across the tubular wall for a number of different concentrations of sodium inside and outside the tubules, and (2) measurements of the passive permeabilities of the walls of the tubules.

Materials that are transported generally cannot readily cross the cell membrane passively under the influence of concentration gradients alone. The currently favored hypothesis of the mechanism of active transport is that the transported material forms a complex with a component of the cell membrane, a carrier, and that this complex can cross the cell membrane more readily than can the free compound. In order to obtain transport against a concentration gradient such carrier systems are assumed to be linked in some manner to the metabolic reactions of the cell; in effect, free energy from cellular metabolism is used to move the compound against a concentration gradient. In the kidney, sodium reabsorption is said to be gradient-time limited, that is, the amount reabsorbed is determined by a limiting gradient against which the pump can move sodium and by the length of time the glomerular filtrate remains in the tubules. This characteristic distinguishes sodium from compounds such as glucose for which there is a maximum rate of reabsorption, the glucose $T_{m}$. If the rate of filtration of glucose is less than the $T_{m}$, essentially all of the glucose is reabsorbed; if it is greater than the $T_{m}$, the rate of reabsorption is $T_{m}$. In terms of the carrier hypothesis of transport the difference between these two types of reabsorptive mechanism is attributed to differences in the affinities of the transported compounds for the carrier. Glucose presumably has a high affinity for its carrier and hence this system shows a sharp saturation effect. On the other hand, sodium is assumed to have a low affinity for its carrier and its transport becomes gradient-time limited.

Most of the detailed studies on the kinetics of active transport systems have utilized cells that can be handled as suspensions, such as red cells and ascites tumor cells. For such systems the phenomenon under study is a transcell membrane transport. In the kidney, however, we are concerned with a transcellular transport. Although a number of good studies on sodium transport in renal tubules are available $[5,6,10,11$, $20,21,25$ ], only the intratubular concentration of sodium has been varied in the experiments reported; thus full sets of data (that is, fluxes of sodium for different intratubular and extratubular concentrations) nec- 
essary for at least an empirical characterization of the transport systems of the proximal and distal tubules are not yet available. In lieu of this, we will use as our transport function one that was derived for the steadystate flux for a relatively simple carrier model of transcell membrane transport [8] and show that with an appropriate choice of parameters we can match the experimental findings on tubular transport that are available.

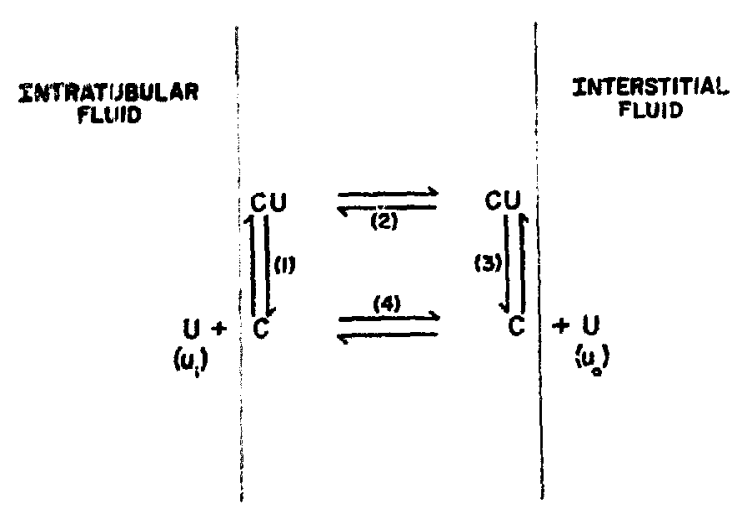

Fig. 5. Diagram of carrier model of active transport.

The model is shown in Fig. 5. It consists of four main steps: (1) the formation of a complex between a carrier (C) and the transported substance (U) at the inner surface of the membrane; (2) transfer of the complex to the outer surface; (3) dissociation of the complex at the outer surface, and (4) transfer of free carrier back to the inner surface. For the sake of generality each of these processes is shown as a reversible process. In order to obtain active transport at least one of these processes must be liaked to cellular metabolism. For the present this can only be introduced on an ad hoc basis as an asymmetry between processes 1 and 3 or as an asymmetry between the two directional transfers of free carrier in process 4. We do know that the linkage cannot be in the transfer of carriersubstrate complex (process 2), for this would make exchange fluxes dependent on cellular metabolism. It should be clear that we are using this as a temporary crutch until more complete data and a better model become available. It should also be stressed, however, that for the purpose of this work we do not need a model that incorporates all of the details of the mechanism of active transport; it need only mimic the empirically determined behavior of the pump. We will neglect the potential difference 
between the inside and outside of the tubules because the transported substance is treated in the model as a nonelectrolyte.

The transport function for such a model is simplest in form when the transfer processes, 2 and 4, are considerably faster than process 1 or 3. In that case the transport function is given by Eq. 57 (see [8]).

$$
T\left(u_{i}, u_{o}\right)=\frac{a u_{i}-u_{o}}{A+B u_{i}+C u_{o}}
$$

Otherwise, the denominator in Eq. 57 also contains a term in the product $u_{i} \cdot u_{0}$. Here $u_{i}$ is the concentration inside the tubule, $u_{o}$ is the concentration outside the tubule, and $T\left(u_{i}, u_{o}\right)$ is the pump flux per unit surface area of the tubule, defined to be positive when directed from the inside to the outside of the tubule. The net flux is the sum of the pump flux and the passive (diffusion) flux, Eq. 58.

$$
F_{\text {net }}=\frac{a u_{i}-u_{o}}{A+B u_{i}+C u_{o}}+k_{u}\left(u_{i}-u_{o}\right)
$$

In Eq. 58, $k_{u}$ is the permeability constant for the tubule. Equation 58 can be written as the difference between two one-way fluxes, $F_{o}$ (flux toward the outside) and $F_{i}$ (flux toward the inside),

$$
\begin{aligned}
& F_{c}=\frac{a u_{i}}{A+B u_{i}+C u_{o}}+k_{u} u_{i}, \\
& F_{i}=\frac{u_{o}}{A+B u_{i}+C u_{o}}+k_{u} u_{o},
\end{aligned}
$$

each of which contains two terms, one attributable to the pump, the other to passive movement. It turns out that if the process that is linked to cellular metabolism is practically irreversible, then $a \gg 1$ and the term $u_{o} /\left(A+B u_{i}+C u_{o}\right)$ becomes very small when compared with $a u_{i} /\left(A+B u_{i}+C u_{0}\right)$. If this term is also small when compared with $k\left(u_{i}-u_{0}\right)$, the leakage flux in Eq. 58 is entirely passive and the punp is a one-way, or irreversible, pump. In this case the maximum gradient is attained when the passive leakage flux exactly balances the one-way pump flux. The pumps involved in amino acid transport in ascites tumor cells seem to be of this type [9]. On the other hand, if the pump term in $F_{i}$ is not negligible, we have a reversible pump; that is to say, if by some means the gradient is made large enough, the sign of the pump term in $\mathrm{Eq} .58$ is reversed; in effect, the large gradient causes the pump 
to run backwards. For the reversible pump, the pump flux decreases as the gradient increases and the maximum gradient attainable occurs when the leak flux just balances the net pump flux. For both types of pumps, the reversible and the irreversible, exchange diffusion can occur [7].

Our first problem was to try to determine the nature of the pump. No direct evidence is available on which to base a decision. However, data on fluxes in the tubules are available. Some estimates of the permeabilities, usually calculated by neglecting the electrical potential gradient $[5,6,21,25]$, are also available. Gertz [5] measured the sodium fluxes into the tubules when these were perfused with a low sodium solution made isosmotic with mannitol. He calculated the permeabilities using the assumptions that the pump flux is negligible under these circumstances and that the transtubular potential can be disregarded. The values he obtained were $3 \cdot 10^{-3} \mathrm{~cm} / \mathrm{min}$ for the permeability of the rat proxinaal tubule and $8.4 \cdot 10^{-4} \mathrm{~cm} / \mathrm{min}$ for the permeability of the rat distal tubule. We note that if the pump is irreversible, the measured inward flux would have to be less than or equal to the true leakage flux because the pump would be acting to oppose the leak. In this case the reported values for the permeabilities must be lower bounds for the true permeabilities. On the other hand, if the pump is actually reversible, part of the inward flux at high gradients could be contributed by the reversed pump and these estimates of the permeabilities must then be upper bounds for the true permeabilities.

Next we calculated the permeabilities from data in the literature, using the assumption that the pump is irreversible, and then calculated the energy cost of the passive leak in mannitol diuresis to see if the computed permeabilities give reasonable values for the energy cost; if not, this would be evidence for a reversible pump. We used three sets of permeahility data for the proximal tubule. From the data of Giebisch et al. [6] we calculated a permeability of $4.3 \cdot 10^{-3} \mathrm{~cm} / \mathrm{min}$ for the proximal tubule and from Ullrich's data (Fig. 6 of [21]) we obtained a value of $13.2 \cdot 10^{-3} \mathrm{~cm} / \mathrm{min}$. Gertz's value of $3 \cdot 10^{-3}$ was the other value used.

The energy cost of the passive leak during mannitol diuresis is given by Eq. 61 :

$$
E=F_{L} \cdot S \cdot R T \ln \frac{u_{o}}{u_{i}}=k\left(u_{o}-u_{i}\right) \cdot S \cdot R T \ln \frac{u_{o}}{u_{i}} .
$$

This represents the minimal energy consumption required to maintain the concentration gradient across the tubular wall. In Eq. $61 F_{L}$ is the 
passive leakage flux and $S$ is the surface area. We calculate this for man in mannitol diuresis, assuming the same sodium gradients are attained as have been reported for the rat $[5,6,10,21,25]$. For the $1.2 \cdot 10^{6}$ proximal tubules in one kidney we assumed a radius of $20 \mu$, and that the gradient was :naintained over a full $2-\mathrm{cm}$ length of each tubule. The concentrations used were $u_{o}=145 \mathrm{meq} / \mathrm{liter}$ and $u_{i}=95 \mathrm{meq} / \mathrm{liter}$. Substituting into Eq. 61, we obtain energy costs of $1.31 \mathrm{cal} / \mathrm{min}, 1.87 \mathrm{cal} /$ min, and $5.76 \mathrm{cal} / \mathrm{min}$, using respectively the permeability given by Gertz [5], the one we calculated from the data of Giebisch et al. [6], and the value given by Ullrich [21]. If we use the metabolic conversion factor of $5 \mathrm{cal} / \mathrm{ml} \mathrm{O}_{2}$, these are equivalent to extra oxygen consumptions of $0.26,0.37$, and $1.15 \mathrm{ml} \mathrm{O}_{2}$ per minute, respectively. To these we must add the cost of maintaining the gradient in the distal tubules. For these, Gertz [5] gives a permeability of $8.4 \cdot 10^{-4} \mathrm{~cm} / \mathrm{min}$ and from Ullrich's data [21] we obtain a value of $4.6 \cdot 10^{-3} \mathrm{~cm} / \mathrm{min}$. We assume a radius of $20 \mu$, a length of $1 \mathrm{~cm}$, a total of $1.2 \cdot 10^{6}$ tubules, and that $u_{i}=25$ meq/liter [25]. Substituting in Eq. 61, we obtain energy costs of 1.63 and $9.0 \mathrm{cal} / \mathrm{min}$ or extra oxygen consumptions of 0.33 and $1.80 \mathrm{ml} \mathrm{O}_{2}$ per minute. Adding the values for the proximal and distal tubules, we obtain an extra oxygen consumption of $0.6-3.0 \mathrm{ml} \mathrm{O}_{2}$ per minute per kidney to maintain the sodium gradients in the proximal and distal tubules in mannitol diuresis. These values are large enough to be measured experimentally even when scaled down for a dog kidney, but ari- not unreasonable oxygen costs in terms of the reported oxygen consumption of the kidney [19]. Thus, although the reported permeabilicies appear to be very large at first sight, the energy cost of the resultant leak fluxes is not so large as to make the irreversible pump model improbable. Of course, the permeability estimates are quite rough and there is some question about their validity because the potentials were not taken into consideration in their calculation. However, this would require integration of the Nernst-Planck equation across the tubular wall and for this both the potential profiles and the concentration profiles would be needed. It is possible to use the permeabilities as calculated but to include the electrical work term in the calculation of the energy cost; this procedure multiplies the foregoing estimates by a factor of $2-3$, giving an energy cost that is still within the reasonable range.

In terms of what is generally known of cellular transport systems and in view of the arguments presented earlier it seems to us reasonable to assume that the sodium pump in the kidney is an irreversible pump. 
For comparative purposes, however, we have calculated the parameters for both reversible and irreversible pumps, in order to illustrate the differences in their characteristics, and have used each in some of our computational work.

\section{Parameters for irreversible fumps}

For an irreversible pump the flux is given by Eq. 62:

$$
T\left(u_{i}, u_{o}\right)=\frac{a u_{i}}{A+B u_{i}+C u_{o}} .
$$

Only three of these parameters are independent; hence we redefine $A$, $B$, and $C$ by dividing numerator and denominator by $a$ to give Eq. 63:

$$
T\left(u_{i}, u_{o}\right)=\frac{u_{i}}{A+B u_{i}+C u_{o}} .
$$

No data are available for which the extratubular concentration $u_{o}$ was varied, so that $A$ and $C$ cannot be estimated separately: hence we define $D=A+C u_{o}$ and try to fit Eq. 64, which will hold only for the one value of $u_{o}$ for which data are available.

$$
T\left(u_{i}, u_{o}\right)=\frac{u_{i}}{D+B u_{i}} .
$$

Finally, since $u$ is treated as a nonelectrolyte in our model, the data on sodium transport were treated as though $\mathrm{NaCl}$ were transported and all fluxes and concentrations oi sodium were multiplied by 2 ; thus all data are for $u_{o}=290$ mmoles/liter.

Proximal tubule. In Table I we give the fluxes we have calculated from data reported by Giebisch et al. [6] and Ullrich [21]. The fluxes reported by Ullich, set II, can be obtained directly from Fig. 6 of his paper [21]; the fluxes in set I were calculated from the data reported by Giebisch et al. [6], using the assumption that the tubules are $20 \mu$ in radius. The two sets differ considerably. Each set was fitted with Eq. 64 with the diffusion term added. For the first set we obtain a permeability constant of $k=4.3 \cdot 10^{-3} \mathrm{~cm} / \mathrm{min}$ and pump parameters $D=345$ $\min / \mathrm{cm}$ and $B=180 \mathrm{~cm}^{2}$-min/mmole. The characteristics of this pump are shown in Fig. 6; note that the net flux is zero at a concentration ratio of $u_{i} / u_{0}=0.62$ as reported by Giebisch et al. [6]. For the flux data 
from Ullrich's paper we calculate a permeability of $13.2 \cdot 10^{-3} \mathrm{~cm} / \mathrm{min}$ and pump parameters $D=\mathbf{7 2}, B=\mathbf{6 5 7}$. The characteristics of this pump and the leak fluxes are shown in Fig. 7. The fluxes in set I may be somewhat low since both Giebisch $e t a l$. [6] and Gertz [5] have also reported fluxes for isosmotic resorption $\left(u_{i}=290\right)$ that are nearer to the value

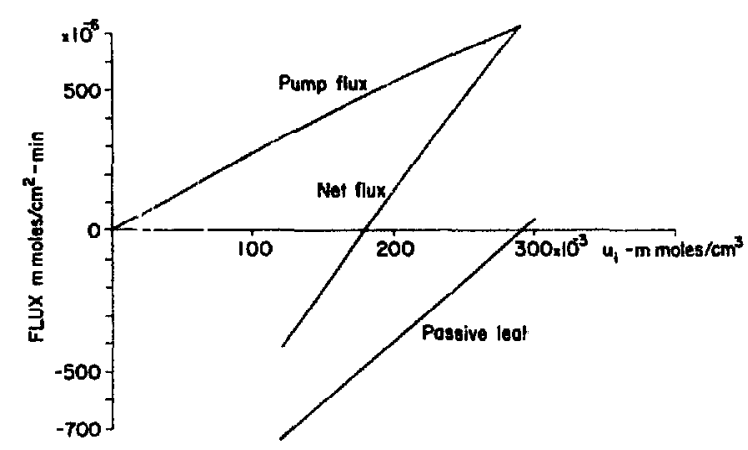

Fig. 6. Characteristics of irreversible pump for proximal tubules, calculated from data of Giebisch et al. [6] (set I of Table 1). The extratubular concentration $u_{o}$ is assumed to be $290 \cdot 10^{-3} \mathrm{mmoles} / \mathrm{cm}^{3}$.

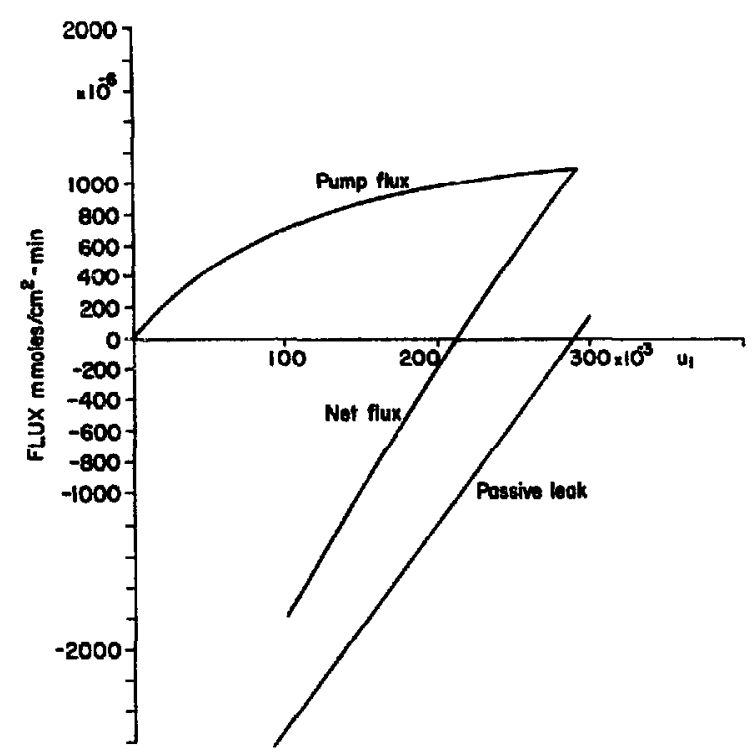

Frg. 7. Characteristics of irreversible pump for proximal tubules, calculated from data of Ullrich [2] (set II of Table I); $u_{o}=290 \cdot 10^{-3} \mathrm{mmoles} / \mathrm{cm}^{3}$.

given by Ullrich. However, Figs. 6 and 7 do show the general characteristics of an irreversible pump and indicate that we have some latitude in varying the pump parameters and the permeability of $u$ in the model. 
TABLE I

FLUXES OF $u$ IN PRUXIMAL TUBULE

\begin{tabular}{lcc}
\hline $\begin{array}{l}u_{i}^{a} \\
(\mathrm{mmoles} / \text { liter })\end{array}$ & $\begin{array}{l}\text { Set } \mathrm{I}^{b} \\
\left(\mathrm{mmoles} / \mathrm{cm}^{\mathrm{s}}-\mathrm{min}\right)\end{array}$ & $\begin{array}{l}\text { Set } \mathrm{II}^{c} \\
\left(\mathrm{mmoles} / \mathrm{cm}^{3}-\mathrm{min}\right)\end{array}$ \\
\hline $\begin{array}{l}0 \\
120\end{array}$ & - & $-3840 \cdot 10^{-6 d}$ \\
200 & $-390 \cdot 10^{-6}$ & - \\
214 & $141 \cdot 10^{-6}$ & - \\
290 & - & 0 \\
& $730 \cdot 10^{-6}$ & $1104 \cdot 10^{-6}$ \\
\hline
\end{tabular}

a $\boldsymbol{u}_{\boldsymbol{o}}=290 \mathrm{mmoles} / \mathrm{liter}$.

${ }^{b}$ Calculated from Giebisch et al. [6].

- Calculated from data in Ullrich [21].

$d$ The flux is defined to be positive when directed out of the tubul

Distal tubule. We do not have as much experimental data for the distal tubule as for the proximal tutule, and that which we do have shows considerable variability. For the maximum gradient in mannitol diuresis the values that have been roported for $u_{i} / u_{0}$ are 0.16 [25], 0.26 [21], 0.34 [5], 0.37 [11], and 0.42 [10]. We have tried to fit the data reported by Ullich $[21]$ but obtain negative values for the parameter $D$; from the nature of the model, the parameters are inherently positive. Using Gertz's value for the permeability [5], the ratio 0.4 for $u_{i} / u_{o}$ for the maximal gradient in mannitol diuresis, and the flux for isosmotic reabsorption given by Ullrich [21], we obtain a pump with the parameters $D=174, B=5.35 \cdot 10^{3}$. A number of others can be chosen that also have fluxes for isosmotic reabsorption approximately one fifth those in the proximal tubule and that give zero net fluxes for $u_{i} / u_{o}$ in the range 0.2-0.4.

\section{Reversible pumps}

In order to fit the available data with a reversible pump we must assume that the reported permeabilities are much too large and choose some value for the permeabilities in order to calculate the pump parameters. We have arbitrarily chosen a permeability of $5 \cdot 10^{-4} \mathrm{~cm} / \mathrm{min}$ for the tubules in order to fit Eq. 57 with the reported data. For set $I$ of the data in Table I we obtain $a=1.71, D=275, B=25$. For comparison with the corresponding irreversible pump (Fig. 6) the characteristics of this 
pump are illustrated in Fig. 8. Note that although the net flux for the two pumps is the same, the pumps differ markedly in their operating characteristics, and that the permeabilities differ considerably for these two cases. For some of our computational work with reversible pumps we used a pump with the parameters $a=1.62, D=89$, and $B=312$, which comes closer to fitting the data in set II of Table I.

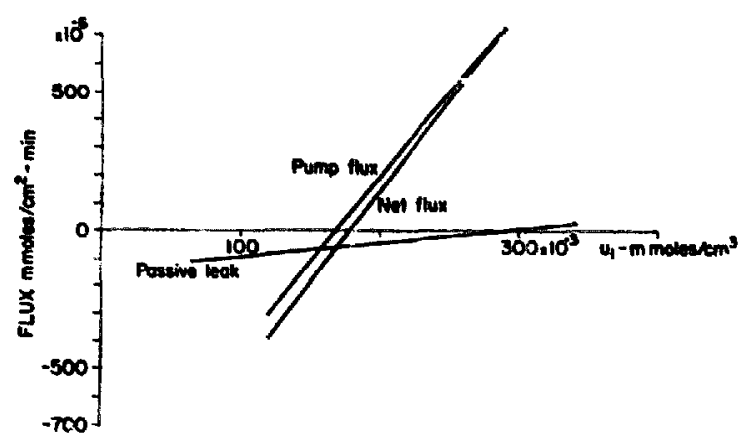

Fig. 8. Characteristics of a reversible pump sor proximal tubules, calculated to fit data of Giebisch et al. [6]; $u_{o}=290 \cdot 10^{-3} \mathrm{mmoles} / \mathrm{cm}^{3}$.

For the distal tubules the data on maximal transtubular gradients give us estimates of 2.4 [10] and 2.7 [11] for the parameter $a$. From Windhager and Giebisch's data, however, we obtain estimates of 2.7 and 6.2 for $a$ in the proximal and distal parts, respectively, of the distal tubule. For some of our computations we have used a pump with the parameters $a=6.6, D=4730, B=357$, which gives the fluxes reported by Gertz [5].

As was mentioned previously, no data are available on which to base estimates of the parameters $A$ and $C$. This is of no consequence for the model of the cortex but $A$ and $C$ are needed for the transport function in the medulla because both intratubular and extratubular concentrations of $u$ change. From the basic model [8] we can say that $C$ must be positive and smaller than $B$. In lieu of any other information we have simply guessed that it will be approximately one half the value of $B$.

PARAMETER VALUES

In choosing parameters for the model, we attempt to model a kidney of the size of the human kidney with approximately $1.05 \cdot 10^{6}$ cortical nephrons and $0.15 \cdot 10^{6}$ juxtamedullary nephrons. 


\section{Lengths}

The lengths of the different tubules vary somewhat, but these are tairly well documented in most texts of histology. The following values seem reasonable: $L_{1}==3 \mathrm{~cm} ; L_{2}=3.5 \mathrm{~cm}(2 \mathrm{~cm}$ for proximal tubule, $0.5 \mathrm{~cm}$ for the Henle segment, $1 \mathrm{~cm}$ for distal); $L_{3}=L_{5}=L_{6}=L_{8}=$ $=1.5 \mathrm{~cm} ; L_{4}=2 \mathrm{~cm} ; L_{7}=1 \mathrm{~cm}$. For the countercurrent exchange model, $L_{9}$ and $L_{10}$ were both taken to be $1.5 \mathrm{~cm}$. For the distributed capillary bed model, an initial estimate of $1.5 \mathrm{~cm}$ is used for $L_{g}$.

\section{Surface areas}

Rough estimates of surface areas per unit length were obtained from estimates of diameters and numbers of the various tubules. These initial estimates are crude and do not take into account the highly folded nature of the cell membranes; some night easily be orders of magnitude off the mark.

$$
\begin{array}{ll}
S_{1}=4.5 \cdot 10^{4} \mathrm{~cm}^{2} / \mathrm{cm} & S_{5}=S_{6}=0.63 \cdot 10^{3} \\
S_{2}=4.4 \cdot 10^{3} & S_{8}=1.5 \cdot 10^{3} \\
S_{4}=S_{7}=0.63 \cdot 10^{3} & S_{9}=S_{10}=2.1 \cdot 10^{3}
\end{array}
$$

\section{Permeabilitics of tubules}

The transfer constants $K$ used in the equations represent products of permeabilities and surface areas per unit length, $K=k S$. The initial estimates of permeabilities were based on the data of Pappenheimer et al. [15] for the capillaries and those of Gertz [5] and Ullrich et al. $[20,21]$ for the nephrons.

Capillaries. $k_{v}=3.8 \cdot 10^{-2} \mathrm{~cm}^{4} /$ milliosmole-min; $k_{n}=2 \cdot 10^{-2} \mathrm{~cm} / \mathrm{min} ;$ $k_{x}, k_{i x^{\prime}}=10^{-2} \mathrm{~cm} / \mathrm{min}$.

Nephrons. $\quad k_{v}=0.25 \mathrm{~cm}^{4} /$ milliosmole-min for proximal tubule (see Ulirich [21]) and descending limb of Henle; $k_{v}=\mathbf{0 . 0 4}$ for distal tubule and collecting duct; $k_{v}=0.002$ for ascending limb of Henle loop; $k_{u}=1-5 \cdot 10^{-4} \mathrm{~cm} / \mathrm{min}$ for reversible pump model and 4-10 $\cdot 10^{-3} \mathrm{~cm} / \mathrm{min}$ for irreversible pump model; $k_{x}=10^{-3} \mathrm{~cm} / \mathrm{min} ; k_{w}=10^{-4}-10^{-5} \mathrm{~cm} / \mathrm{min}$ (mannitol). 
As indicated in the previous section, different permeabilities must be used for $u$ depending on whether we use an irreversible pump or a reversible pump in the model.

Initial values

The flow rates in the capillaries represent plasma flow rates.

Volume flow rates. $\quad v_{1}(0)=236.5 \mathrm{~cm}^{3} / \mathrm{min} ; \quad v_{2}(0)=54.0 \mathrm{~cm}^{3} / \mathrm{min}$; $v_{4}(0)=7.72 \mathrm{~cm}^{3} / \mathrm{min} ; \quad v_{9}(0)=26.75 \mathrm{~cm}^{3} / \mathrm{min}$.

Initial concentrations. $\quad p(0)=2 \cdot 10^{-3}$ milliosmoles $/ \mathrm{cm}^{3}$ (from Pitts [17]); $u_{1}(0)=u_{2}(0)=u_{4}(0)=u_{9}(0)=0.280$ milliosmoles $/ \mathrm{cm}^{3} ; x_{1}(0)=$ $=x_{2}(0)=x_{4}(0)=x_{8}(0)=0.02$ milliosmoles $/ \mathrm{cm}^{3} ; \quad w_{1}(0)=w_{2}(0)=$ $=w_{4}(0)=w_{9}(0)$-to be used when we consider osmotic diuresis; otherwise 0 .

\section{DISCUSSION AND CONCLUSION}

We wish to emphasize that we are not trying to build a detailed model of sodium transport or for that matter of the kidney. We already have perfect models, abundant in detail and variety, in the real kidneys of different species. Our purpose is to construct a model, stripped of superfluous detail, that incorporates what are apparently the most significant features of the architecture of the kidney and that describes the functioning of the basic units. We wish to see to what extent such a model can explain the concentrative function of the kidney. In a sense this is a feasibility study. We hope and expect to obtain further insight into the nature of rena' function. In fact it is obvious that the very process of formulating the model helped us to clarify our own ideas and to define those features of renal function for which we need more detailed experimental data. In the course of this, it has become apparent that our knowledge of many of the basic physical parameters required in the model is quite imprecise.

A number of problems have been raised; their resolution depends on further experimental work. First, there is the possibility that the commonly accepted countercurrent exchange model of the medullary capillaries is in error and that a distributed capillary bed might be a truer picture. Indeed it seems possible that the distribution function of the capillaries in the medulla is a major determinant of the concentration profile attained in the interstitial fluid of the medulla and hence in the 
concentrative sunction of the medulla; we hope that computational studies on the nodel will indicate whether this is a possible explanation. Second, there are some questions concerning the nature of the sodium pump that have not been fully resolved. Although we have favored an irreversible pump, the data are not so clear-cint as to eliminate the possibility that the pump is reversible.

The model has been formulated with the intention of carrying out numerical studies on a digital computer. Hence we are not forced to make further mathematical approximations to subject the differential equations to analysis. Even so there are a number of difficulties. It is usually not difficult to integrate numerically systems of 20 or 30 wellbehaved simultaneous ordinary differential equations, provided initial conditions are known. In this case we have a multiple-point boundaryvalue problem of some complexity, a very much more difficult problem to solve numerically. We intend first to examine the behavior of the model of the cortex in isolation and then the behavior of the various tubules in the medulla using a fixed concentration-distance profile in the medullary interstitial fluid, in each case varying individual parameters in order to satisfy the over-all material balance conditions for solvent and solutes that any mathematical solution of the equations must satisfy. Then we hope to integrate the full set of equations for the medulla and finally to incorporate the models of the cortex and medulla into one composite model of the kidney. The results of these computational studies will be published in subsequent papers.

\section{REFERENCES}

1 F. Bergmann and S. Dikstein. The theory of the transfer, through the walls of biological tubules, of solutes in a moving fluid, $J$. Physiol. 145(1959), 14-21.

2 A. S. V. Burgen, A theoretical treatment of glucose reabsorption in the kidney, Canad. J. Biochem. Physiol. 34(1956), 446-474.

3 V. P. Dole, Back-diffusion of urea in the mammalian kidney, Amer. J. Physiol. 139(1943), $504-513$.

4 S. K. Friedlonder and M. Walser, Some aspects of flow and diffusion in the proximal tubule of the kidney, J. Theoret. Biol. 8(1964), 87-96.

i K. H. Gertz, Transtubuläre Natriumchloridflüsse und Permeabilität für Nichtelektrolyte in proximalen und distalen Konvolut der Rattenniere, Pfliiger's Arch. Ges. Pihysiol. 276(1963), 336-356.

6 G. Giebisch, R. M. Klose, G. Malnic, W. J. Sullivan, and E. E. Windhager, Sodium movement across single perfused proximal tubules of rat kidneys, J. Gen. Physiol. 47(1964), 1175-1192. 
7 T. Hoshiko, R. E. Swanson, and M. B. Visscher, Excretion of $\mathrm{Na}^{22}$ and $\mathrm{K}^{42}$ by the perfused bullfrog kidney and the effect of some poisons, Amer. J. Physiol. 184(1956), $542-547$.

$8 \mathrm{~J}$. A. Jacquez, The kinetics of carrier-mediated transpor:: Stationary-state approximations, Biochim. Biophys. Acta 79(1964), 318-328.

9 R. M. Johnstone and P. G. Scholefield, Amino acid transport in tumor cells, Adv. Cancer Res. 9(1965), 143-226.

$10 \mathrm{M}$. Kashgarian and H. Stockle, Electrochemical potential difference of $\mathrm{Na}$ and $\mathrm{Cl}$ during zero net flow in single rat kidney tubules, Proc. 22nd Internat. Congr. Union Physiol. Sci. (Leiden), 1962, 2, Abstr. No. 253.

11 M. Kashgarian, H. Stockle, C. W. Gottschalk, and K. J. Ullrich, Transtubular electrochemical potentials of sodium and chloride in proximal and distal renal tubules of rats during antidiurc is and water diuresis (diabetes insipidus), Pflïger's Arch. Ges. Physiol. :77(1963), 89.

12 R. B. Kelman, $A$ theoretical note on exponential flow in the proximal part of the mammalian nephron, Bull. Math. Biophys. 24(1962), 303-317.

13 W. Kuhn and A. Ramel, Aktiver Saiztransport als möglicher (und wahrscheinlicher) Einzeleffekt bei der Harnkonzentrierung in der Niere, Helv. Chim. Acta 49(1959), 628-660.

14 D. B. Moffat. and J. Fourman, The vascular pattern of the rat kidney, J. Anat. ar(1963), 543-553.

15 J. R. Pappenheimer, E. M. Renkin, and L. M. Borrero, Filtration, diffusion and m lecular sieving through peripheral capillary membranes. A contribution to the ore theory of capillary permeability, Amer. J. Physiol. 167(1951), 13-46.

16 G. G. 1 inter and J. L. Shohet, Origin of sodium concentration profile in the renal medulla, Nature $\mathbf{9 0 0 ( 1 9 6 3 ) , 1 - 8 .}$

17 R. F. Pitts, Physiology of the kidncy and body fluids, Year Book Med. Publ., Chicago, 1963.

18 K. K. Plak ze and E. W. Pfeiffer, Blood vessels of the mammalian renal medulla, Science 146(1964), 1683-1685.

$19 \mathrm{~K}$. Thurau, Renal Na-reabsorption and $\mathrm{O}_{2}$-uptake in dogs during hypoxia and hydrochlorothiazide infusion, Proc. Soc. Exp. Biol. Med. 106(1961), 714-717.

20 K. J. Ullrich, G. Rumrich, and G. Fuchs, Wasserpermeabilität und transtubularer Wasserfluß corticaler Nephronabschnitte bei verschiedenen Diuresezuständen, Pflitger's Arch. Ges. Physiol. 980(1964), 99-119.

21 K. J. Ullich, Analysis of renal function by microtechniques, Proc. 23 rd Internat. Congr. Union Physiol. Sci. (Tokyo), 4(1965), 53-66.

22 A. M. Walker, P. A. Bott, J. Oliver, and M. C. Mac Dowell, The collection and analysis of fluid from single nephrons of the mammalian kidney, Amer. J. Physiol. $134(1941), 580-595$.

23 M. Walser and B. H. B. Robinson, Renal discrimination between calcium and strontium, Johns Hopkins Hosp. Bull. 111(1962), 20-34.

24 L. G. Wesson, Jr., A theoretical analysis of urea excretion by the mammalian kidney, Amer. J. Physiol. 179(1954), 365-371.

25 E. E. Windhager and G. Giebisch, Micropuncture study of renal tubular transfer of sodium chloride in the rat, Amer. J. Physiol. 200(1961), 581-590. 